\title{
IMRT dose verification considering passing rate and respiratory motion
}

\author{
KAI XIE, HONGFEI SUN, TAO LIN, LIUGANG GAO, JIANFENG SUI and XINYE NI \\ Radiotherapy Department, Second People's Hospital of Changzhou, \\ Nanjing Medical University, Changzhou, Jiangsu 213003, P.R. China
}

Received June 29, 2017; Accepted March 28, 2018

DOI: $10.3892 / \mathrm{ol} .2018 .8724$

\begin{abstract}
The aim of the present study was to investigate the association between the dynamic intensity-modulated radiation therapy planned $\gamma$ analysis passing rate and respiratory amplitude (A) and period (T) for different tumor volumes. A total of 30 patients with malignant lung tumors were divided into three groups: $\mathrm{A}$; $\mathrm{B}$; and $\mathrm{C}$. The average tumor volumes (V) in the A, B and C groups were 635, 402 and $213 \mathrm{~cm}^{3}$, respectively. The simulated A values were set at $0,5,10,15,20$ and $25 \mathrm{~mm}$. The $\mathrm{T}$ values were set at 4, 5 and $6 \mathrm{sec}$. The $\gamma$ analysis passing rate was calculated under different conditions (dose difference, $3 \%$; distance difference, $3 \mathrm{~mm}$ ). Compared with the $\gamma$ analysis passing rate in the A group $(A=0$, static; $T=4$, $5,6 \mathrm{sec})$, the $\gamma$ analysis passing rate deviation $(\mathrm{A}=5 \mathrm{~mm})$ was $<3.3 \%$. However, this difference was not statistically significant $(\mathrm{P}>0.05)$. With a gradual increase in A value, the passing rate decreased. The deviation between the 3 groups was $<2.5 \%$ at the same A value ( $\mathrm{T}=4,5$ and $6 \mathrm{sec})$. A descending trend of passing rate with increased $\mathrm{A}$ value was revealed. At the same $\mathrm{A}$ and $\mathrm{T}$ values, the passing rate decreased with decreased tumor volume. At the same tumor volume, the passing rate decreased when the A value increased. The respiratory cycle was not demonstrated to be associated with the passing rate. Overall, these results suggest that the A value should be controlled in clinical radiotherapy.
\end{abstract}

\section{Introduction}

Intensity-modulated radiation therapy (IMRT) is used to deliver a high dose of radiation to a large area, particularly in lung tumors $(1,2)$. This treatment requires high quality assurance and quality control. Dose verification for individual

Correspondence to: Dr Xinye Ni, Radiotherapy Department, Second People's Hospital of Changzhou, Nanjing Medical University, 29 Xinglong Street, Changzhou, Jiangsu 213003, P.R. China E-mail: nxy2000@aliyun.com

Key words: intensity-modulated radiation therapy, respiratory motion, passing rate, lung tumor, respiratory cycle patients prior to treatment is required to ensure accurate treatment (3).

Dose verification of IMRT is performed using single- or multiple-field synthesis, and a slow photosensitive film or an ionization chamber matrix needle (4-6). The ionization chamber matrix method is widely used for its convenience, high repeatability and high digitalization (7). The ionization chamber matrix is employed to irradiate the target area vertically and to measure the beam angle $0^{\circ}(8)$. At different gantry angles, the multileaf collimator (MLC) is affected by gravity, friction, inertia and other factors (9). This effect results in a difference between the actual MLC leaf error and that of the planning system (10). Therefore, in the present study, the rack angle zero method was used to avoid the effects of rack accuracy on the actual dose distribution of IMRT (11).

Computed tomography (CT) positioning images used in radiotherapy planning are static images. However, the respiratory motion of the patient during scanning alters the position of the lung tumors and surrounding organs, and affects the irradiation dose delivered to the target areas and the organs at risk $(12,13)$. Respiratory motion also affects image acquisition, including that of cone beam CT (14). Based on the IMRT of an MLC, the deviation of the target area irradiation dose caused by respiratory motion was $\leq 47.8 \%$ (15).

The $\gamma$ analysis method was applied in the present study (16). The association between the dynamic IMRT planned $\gamma$ analysis passing rate and respiratory amplitude (A), and tumor volume, was investigated using a semiconductor detector and respiratory motion platform. The experiments were performed to provide a reference for the design and evaluation of IMRT plans.

\section{Patients and methods}

Patients. A total of 30 patients with lung tumors were admitted to The Second People's Hospital of Changzhou (Changzhou, China) and underwent radiation therapy between July 2016 and December 2016. Patients comprised 18 males and 12 females with a mean age of $44.5 \pm 7.9$ years (age range, 36-52 years). The patients were divided into groups A, B and C, with each group comprising 10 patients. The average volumes of the tumor target area (PTV) were 635, 402 and $213 \mathrm{~cm}^{3}$ in groups $\mathrm{A}, \mathrm{B}$ and $\mathrm{C}$, respectively. The volume ratio of the three groups was $\sim 3: 2: 1$. The prescribed doses of PTV were 60 Gy for 
all patients, administered in 30 fractions. The whole course of treatment was $\sim 42$ days. The present study was approved by the Medical Ethics Committee of The Second People's Hospital of Changzhou (Changzhou, China), and all patients provided written informed consent for participation.

Equipment and materials. An Infinity linear accelerator (Elekta Instrument AB, Stockholm, Sweden) was used in the present study. The MLC possessed 80 pairs of leaves, and the width of each leaf was $5 \mathrm{~mm}$. The algorithm of the Monaco treatment planning system (TPS, version 5.11.01; Elekta Instrument AB) was the Monte Carlo calculation. The Matrixx evolution dose verification system adopted a 2D ionization chamber array system (IBA Dosimetry, Bartlett, TN, USA). This system was composed of 1,020 air ionization chambers and arranged in a $32 \times 32$ matrix. The ionization chamber was $4.5 \mathrm{~mm}$ in diameter and $5 \mathrm{~mm}$ in height, with an adjacent spacing of $7.62 \mathrm{~mm}$ and a sensitive volume of $0.08 \mathrm{~cm}^{3}$. The effective measurement range was $24.4 \times 24.4 \mathrm{~cm}$. The periphery of the matrix system was wrapped in a $5 \mathrm{~cm}$ polymethyl methacrylate material (MiniPhantom; IBA Dosimetry, Bartlett, TN, USA). The simulated respiratory motion apparatus was a 008PL dynamic platform (CIRS, Norfolk, VA, USA). The maximum A value of the simulated respiratory motion range was $\sim 25 \mathrm{~mm}$. The respiratory frequency and A value were set using the program control. In the present study, the sine wave function sin was used to simulate the human respiratory waveform. The quality assurance (QA) phantom center (tumor center) was set at the center of the accelerator when $A=0$ (17). The overall QA experimental device is demonstrated in Fig. 1, with the Matrixx evolution device placed on the dynamic platform.

Plan design. The QA method used (18) is briefly described as follows: The CT scan image was transmitted to the Monaco planning system for 3D reconstruction. The radiologist outlined the patients' target area in accordance with the ICRU62 report (19), clinical examination and imaging technology. Radiation was administered using a 6-MV X-ray with a prescription dose of $60 \mathrm{~Gy}$, which reached 95\% PTV. The irradiation was conducted 30 times. The dynamic IMRT plans of the 30 patients were designed using the Monaco planning system. Using the Monte Carlo algorithm, a computational grid of $0.3 \times 0.3 \mathrm{~cm}$ was obtained. Each patient plan was transferred to the QA module and the rack angle was returned to 0 . The QA phantom coronal plane isocenter dose was outputted. The average $\gamma$ analysis passing rate of the patients was $98 \%$ in the simulated static state.

Data acquisition. The respiratory apparatus was horizontally placed on the treatment bed to ensure that the forward and backward directions of movement were parallel with the bed. The QA phantom was placed on the respiratory apparatus in order that the effective measurement point of the $2 \mathrm{D}$ matrix was located at the isocenter layer of the accelerator. The respiratory motion was in the head-to-foot direction, which is the most common direction of motion of lung tumors (20). The motion function was the sinusoidal function. In a normal resting state, respiratory frequency is $16-20$ breaths/min (21). Shimizu et al (22) demonstrated a lung tumor marker

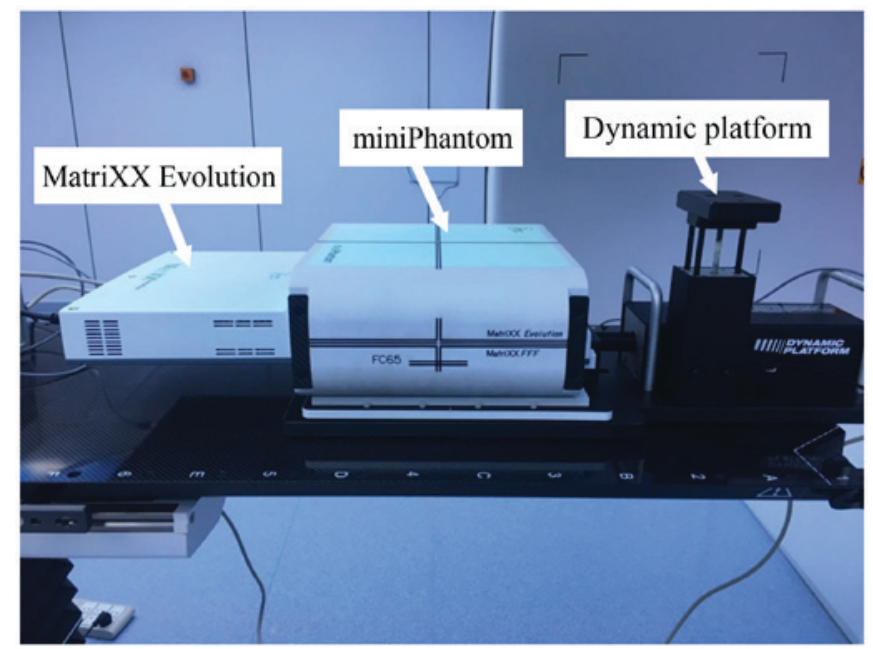

Figure 1. Set-up of experimental equipment.

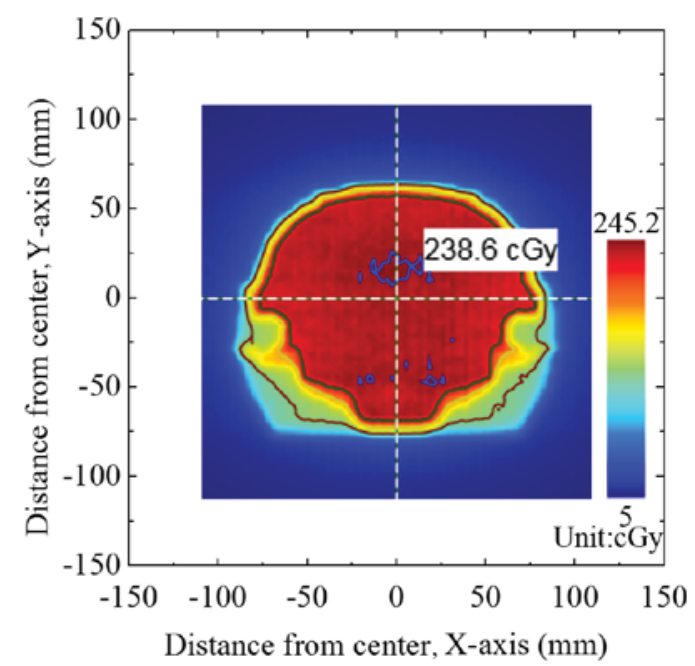

Figure 2. Outputted dose fluxgraph example of the treatment planning system plan in group B.

movement range of $6.8-15.9 \mathrm{~mm}$. The A values used were $0,5,10,15,20$ and $25 \mathrm{~mm}$. The $\mathrm{T}$ values were set as 4,5 and $6 \mathrm{sec}$. The respiratory motion simulation period was $\geq 4.9$ sec in accordance with the dynamic platform. Therefore, the $25 \mathrm{~mm} / 4 \mathrm{sec}$ groups were absent. Thus, a total of 17 control experiments were performed for $\mathrm{A}, \mathrm{B}$ and $\mathrm{C}$ groups. The passing rates were measured in the $\mathrm{A}, \mathrm{B}$ and $\mathrm{C}$ groups, with $3 \% / 3 \mathrm{~mm}$ (dose deviation, 3\%; distance deviation, $3 \mathrm{~mm}$ ) as the standard.

Statistical analysis. Data are expressed as the mean \pm standard deviation and were analyzed using the SPSS statistical software package version 20.0 software (IBM Corp., Armonk, NU, USA). All experiments were performed in triplicate. The A values and $\gamma$ analysis passing rates of different tumor volumes were analyzed using one-way analysis of variance (ANOVA). An unpaired Student's t-test was used for two group comparisons and one-way ANOVA followed by Tukey's test was used for three or more group comparisons. $\mathrm{P}<0.05$ was considered to indicate a statistically significant difference. 
A

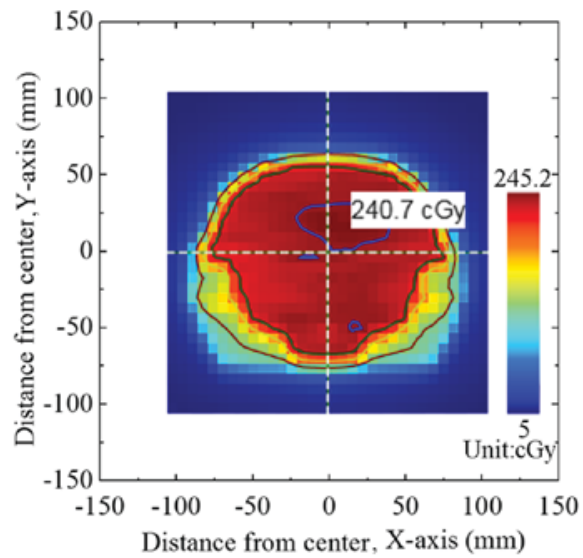

C

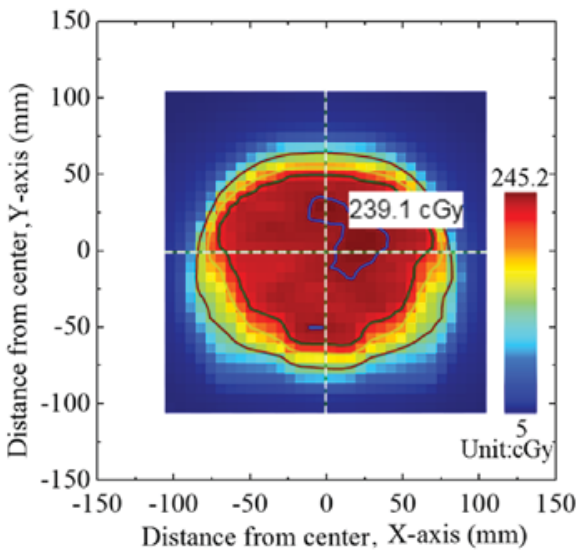

B

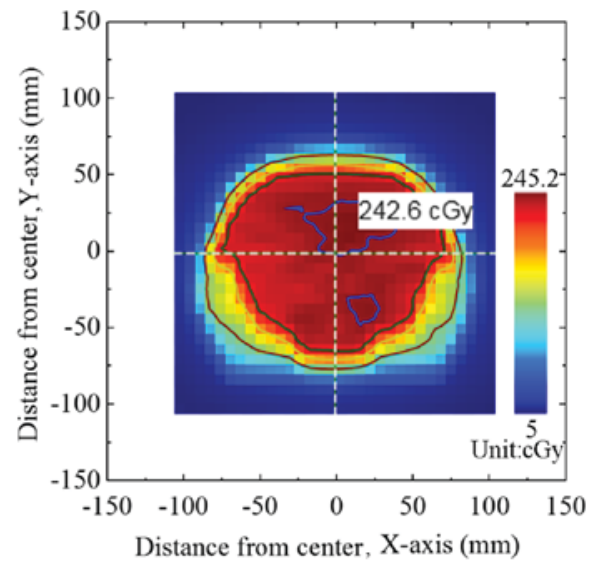

D

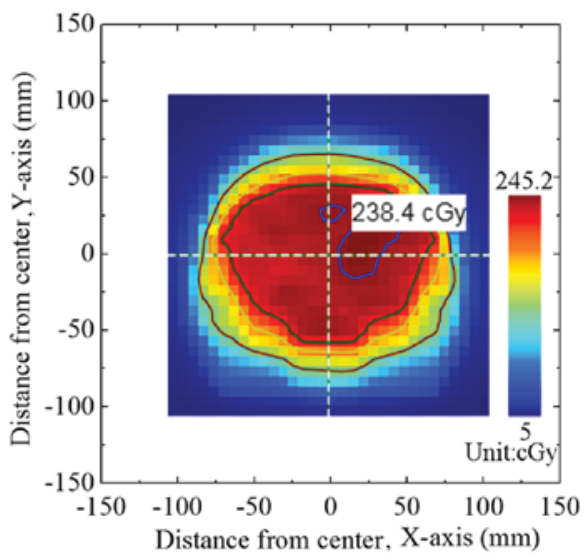

Figure 3. Measured dose fluxgraphs in group $\mathrm{A}$ at $\mathrm{T}=4 \mathrm{sec}$, and at (A) $\mathrm{A}=5 \mathrm{~mm}$; (B) $\mathrm{A}=10 \mathrm{~mm}$; (C) $\mathrm{A}=15 \mathrm{~mm}$, and (D) $\mathrm{A}=20 \mathrm{~mm}$. $\mathrm{T}$, period; $\mathrm{A}$, respiratory amplitude.

\section{Results}

Comparison of the measured dose fluxgraph and the output dose fluxgraph. Fig. 2 presents the output dose fluxgraph from the TPS plan of group A. Fig. 3 presents the dose fluxgraph in group $A$ at $A=5,10,15$ or $20 \mathrm{~mm}(\mathrm{~T}=4 \mathrm{sec})$. Figs. 4 and 5 present the corresponding dose fluxgraphs in the $\mathrm{B}$ group ( $\mathrm{T}=5$ and $6 \mathrm{sec}$ ). Figs. 3, 4 and 5 demonstrate that the high-dose area (where dose was $>90 \%$ of the maximal dose) decreased with increased A values. The low-dose area (where dose was $<60 \%$ of the maximal dose) remained constant.

Association of the $\gamma$ analysis passing rate, and the $A$ and $T$ values. The passing rate deviation was $<3.3 \%$ when $\mathrm{A}=5 \mathrm{~mm}$ ( $\mathrm{T}=4,5$ and $6 \mathrm{sec}$ ) compared with the passing rate (static) in the A group (Fig. 6). However, this was not statistically significant $(\mathrm{P}>0.05)$. The passing rate decreased when the $\mathrm{A}$ value increased from $5 \mathrm{~mm}$. When the A value exceeded $10 \mathrm{~mm}$, the passing rates significantly differed from that of the static state $(\mathrm{P}<0.05)$. When the A values were $10,15,20$ and $25 \mathrm{~mm}$, the passing rate deviations were 13.9, 30.7, 40.7 and $48.3 \%$, respectively $(\mathrm{T}=6 \mathrm{sec})$. The passing rate deviation among the 3 groups was $<2.5 \%$ at the same A value ( $\mathrm{T}=4,5$ and $6 \mathrm{sec}$ ).

The passing rate of group B decreased with increased A value (Fig. 7), reflecting the results of group A. The maximum passing rate deviation among the 3 groups was $2.3 \%$ at the same $\mathrm{A}$ value $(\mathrm{P}>0.05)$.
The passing rate of group $\mathrm{C}$ was similar to that of group B (Fig. 8). However, with increasing A values, the descending trend of group $\mathrm{C}$ was more evident compared with that of group B.

Association between the tumor volume and passing rate. The association between respiratory amplitude, volume and passing rate under different breathing cycles was analyzed. When the average tumor volume decreased from $635 \mathrm{~cm}^{3}$ (group A) to $402 \mathrm{~cm}^{3}$ (group B), the maximum passing rate deviation was $1.7 \%$, ( $>>0.05$; Fig. 9). However, when the average tumor volume decreased from $402 \mathrm{~cm}^{3}$ (group B) to $213 \mathrm{~cm}^{3}$ (group C), the passing rate significantly decreased, with a maximum deviation of $20.6 \%$ ( $\mathrm{T}=4 \mathrm{sec}$ ). The association between the passing rate and tumor volume at $\mathrm{T}=5$ and $6 \mathrm{sec}$ were similar to that at $\mathrm{T}=4 \mathrm{sec}$ (Figs. 10 and 11).

\section{Discussion}

The correct implementation of IMRT is not achievable without assessment of the radiation field output dose. Tumor motion affects the accuracy of the dose distribution (23). IMRT plan conformal indices may predict the effects of respiratory motion on the dose distribution (24).

Comparison of the TPS dose fluxgraph and the measured dose fluxgraph revealed that the increase in A value reduced high-dose target areas, enlarged low-dose target areas 
A

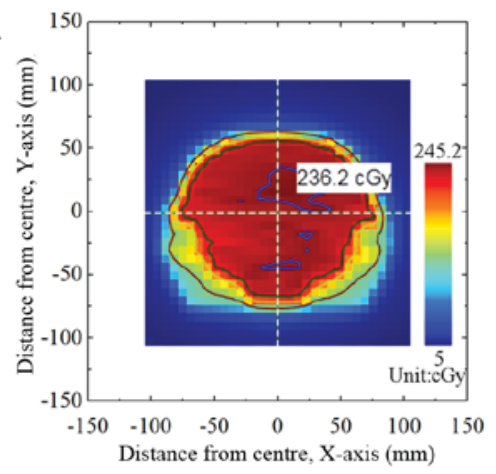

B

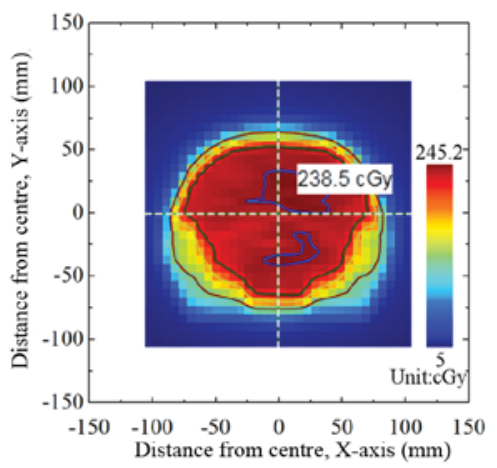

C

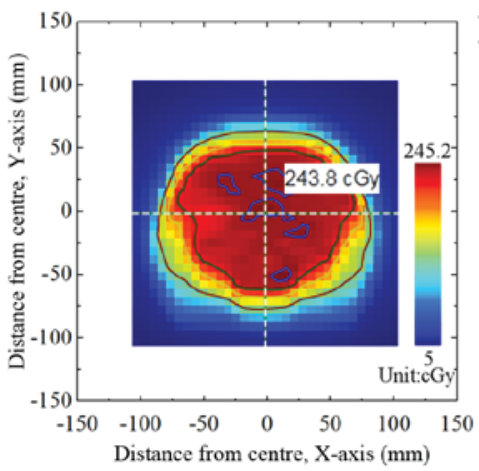

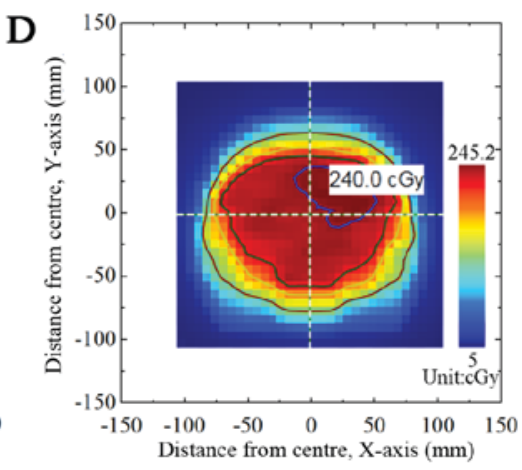

Figure 4. Measured dose fluxgraphs in group A at $\mathrm{T}=5 \mathrm{sec}$, and at (A) $\mathrm{A}=5 \mathrm{~mm}$; (B) $\mathrm{A}=10 \mathrm{~mm}$; (C) $\mathrm{A}=15 \mathrm{~mm}$; (D) $\mathrm{A}=20 \mathrm{~mm}$, and (E) $\mathrm{A}=25 \mathrm{~mm}$. T, period; A, respiratory amplitude.

A

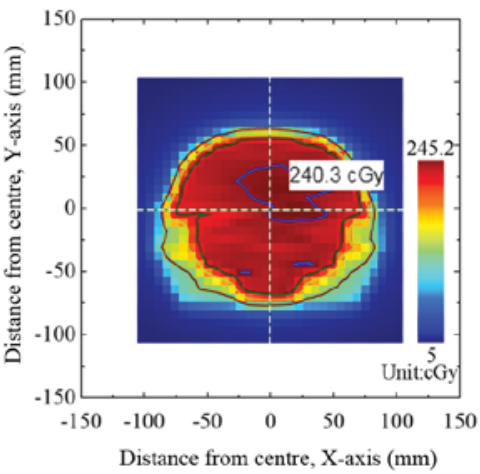

B

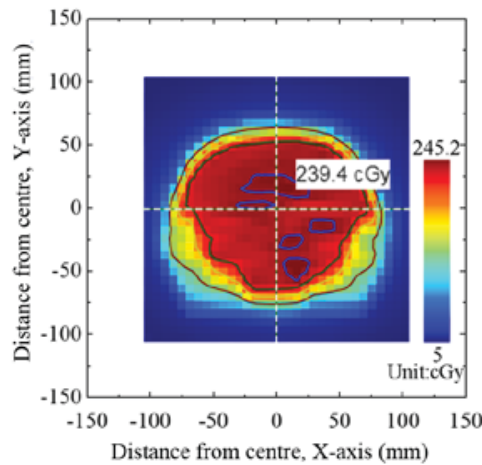

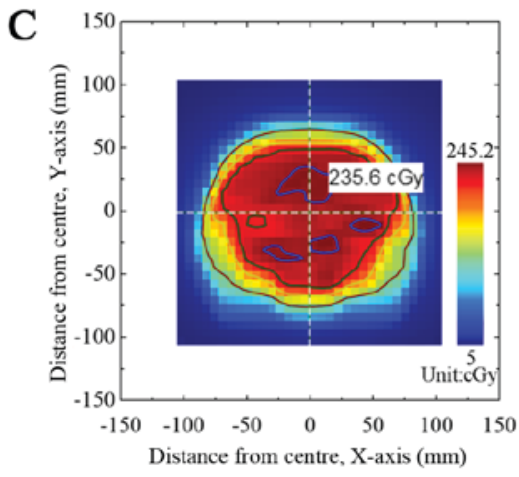
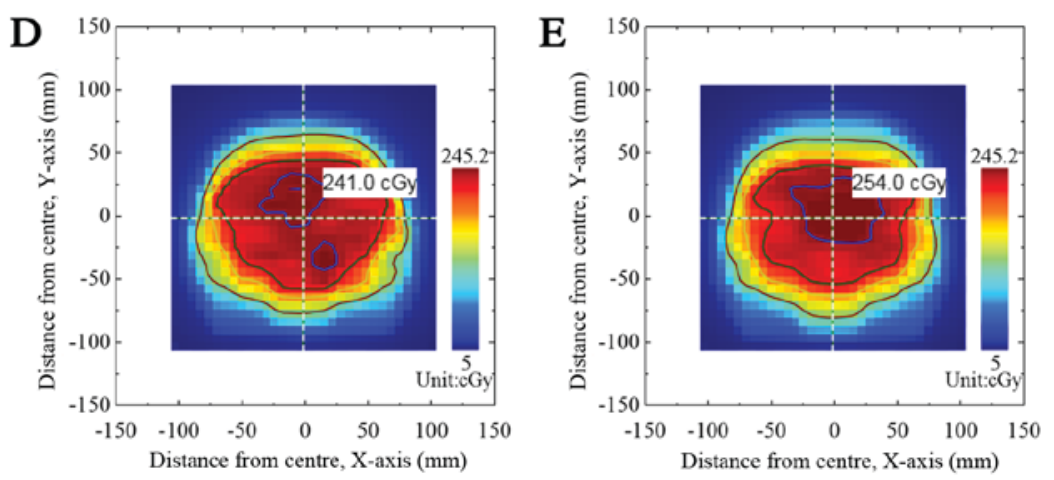

Figure 5. Measured dose fluxgraphs in group $A$ at $T=6 \mathrm{sec}$, and at (A) $\mathrm{A}=5 \mathrm{~mm}$; (B) $\mathrm{A}=10 \mathrm{~mm}$; (C) $\mathrm{A}=15 \mathrm{~mm}$; (D) $\mathrm{A}=20 \mathrm{~mm}$, and (E) $\mathrm{A}=25 \mathrm{~mm}$. $\mathrm{T}$, period; A, respiratory amplitude.

and blurred the isodose margin. The respiratory motion caused dose perturbation and resulted in a blurred isodose margin (25).
Increased A value reduced the passing rate (Figs. 6-8). The A value deviation was statistically significant at $10 \mathrm{~mm}(\mathrm{P}=0.001)$. When the A value was $<5 \mathrm{~mm}$, the passing 


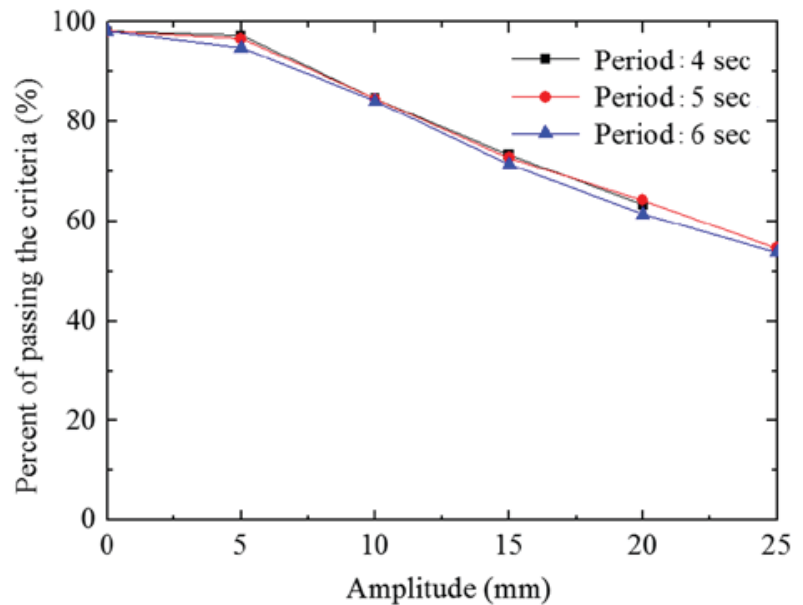

Figure 6 . Association between the passing rate and respiratory amplitude in group $\mathrm{A}$.

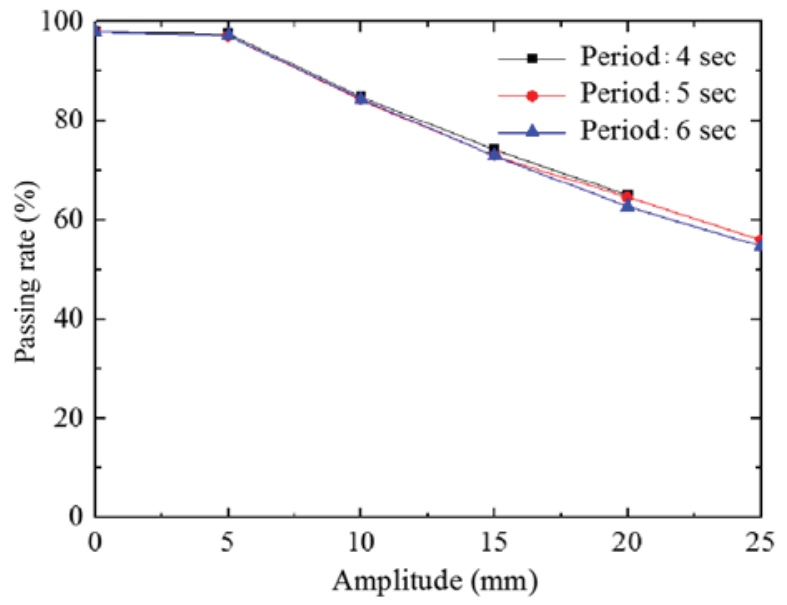

Figure 7. Association between the passing rate and respiratory amplitude in group B.

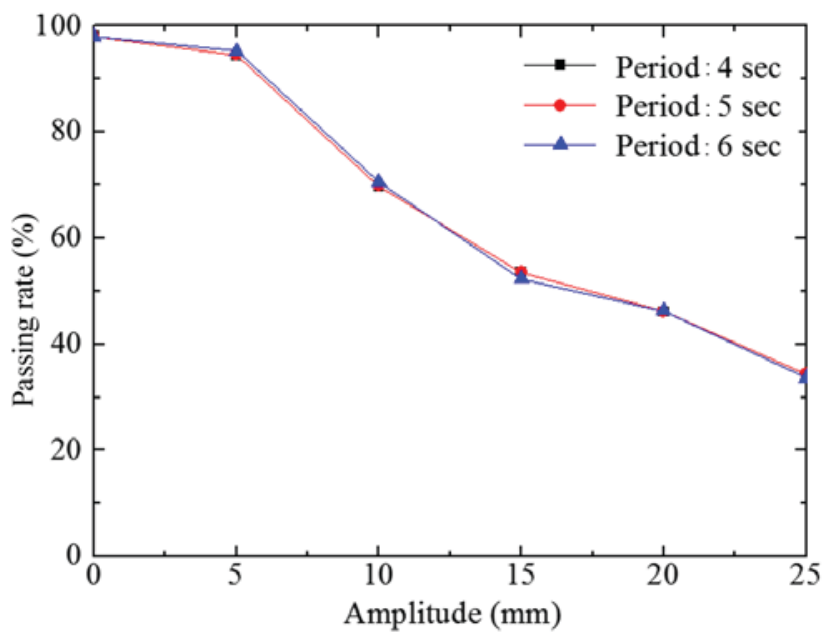

Figure 8. Association between the passing rate and respiratory amplitude in group C.

rate of the irradiation field was $>90 \%$. Schaefer et al (26) investigated the dose distribution at an A value of $8 \mathrm{~mm}$. The

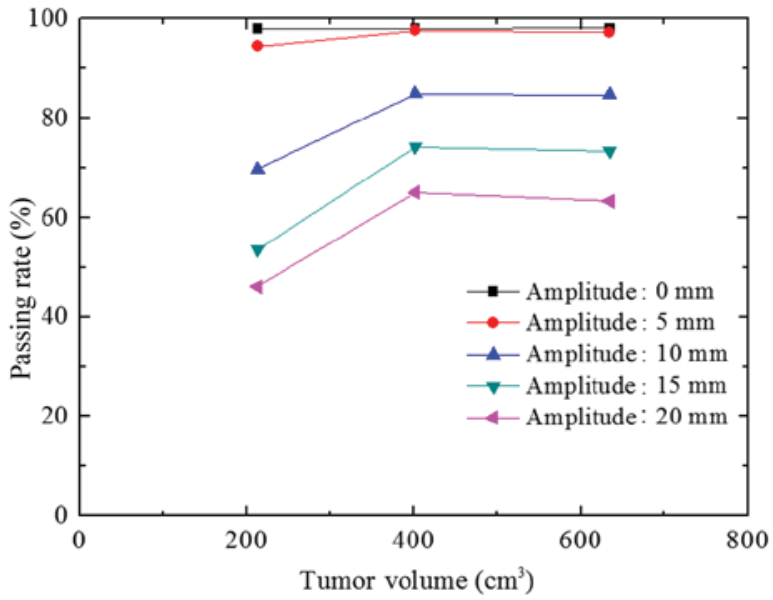

Figure 9. Association between the respiratory amplitude and tumor volume ( $\mathrm{T}=4 \mathrm{sec}$ ). $\mathrm{T}$, period.

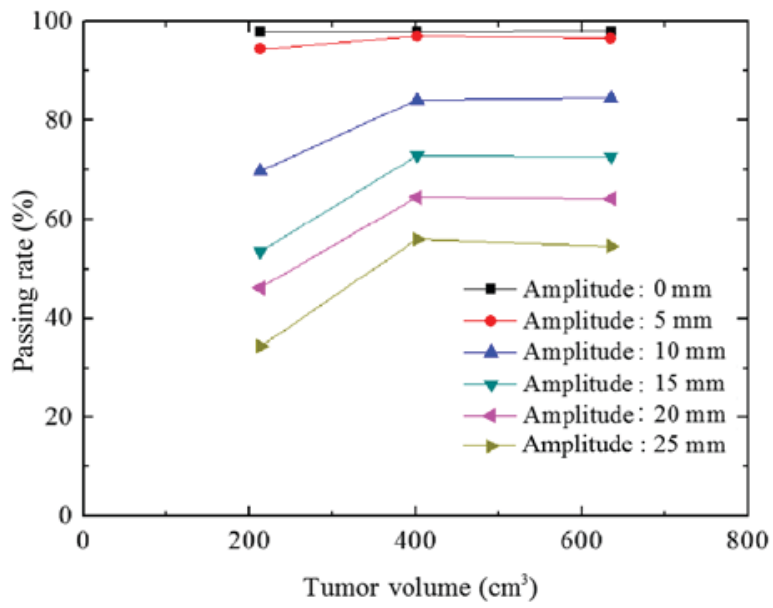

Figure 10. Association between the respiratory amplitude and the tumor volume $(\mathrm{T}=5 \mathrm{sec}) . \mathrm{T}$, period.

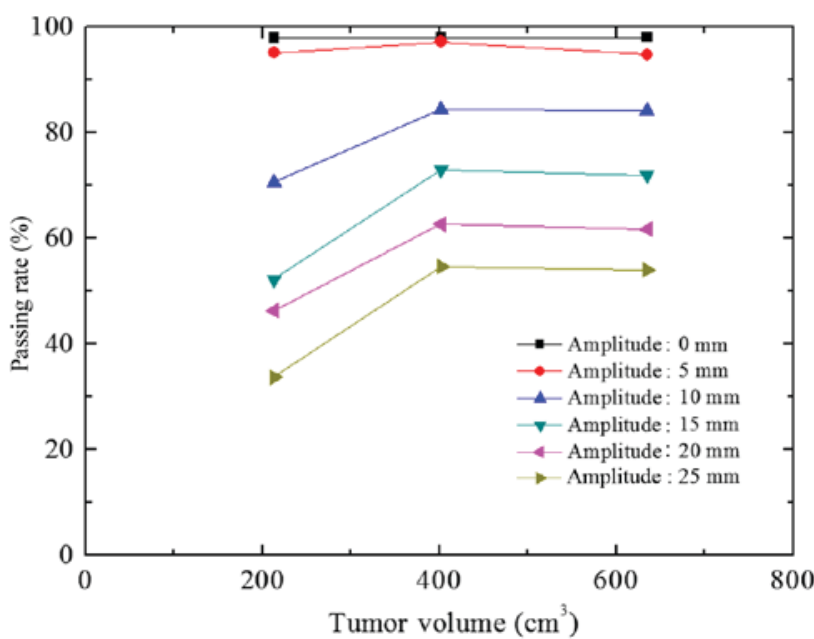

Figure 11. Association between the respiratory amplitude and the tumor volume $(\mathrm{T}=6 \mathrm{sec}) . \mathrm{T}$, period.

results demonstrated that the deviation was usually $<5 \%$. This is likely due to the respiratory motion caused by movement 
of the target area, suggesting that the irradiation field and target area moved in association with each other. When the A value decreased, the ratio of the deviation area accounting for the target diminished. This effect resulted in the ascending trend of the passing rate. When the size of the irradiation field was increased, the ratio of the deviation area accounting for the target area also increased. This effect resulted in the descending trend of the passing rate.

Figs. 6-8 demonstrate the lack of statistical significance of the association between the passing rate and $\mathrm{T}$ value $(\mathrm{P}>0.05)$. This result was likely because the respiratory period was relatively short compared with the overall treatment time.

When the tumor volume was decreased from $635 \mathrm{~cm}^{3}$ (group A) to $402 \mathrm{~cm}^{3}$ (group B), the passing rate decreased to $5.6 \%$, and when the tumor volume was decreased from $402 \mathrm{~cm}^{3}$ (group B) to $213 \mathrm{~cm}^{3}$ (group C), the passing rate significantly decreased $(\mathrm{P}=0.004)$. These results indicate that the passing rate was closely associated with tumor volume. This result supports that of decreased passing rate with increased A value, as the proportion of the tumor exceeding the irradiation field due to respiratory motion would increase. These results suggest that the effect of respiratory motion on the dose distribution should be considered more carefully for smaller tumors (26).

In lung tumor radiotherapy, the deviation in dose distribution caused by respiratory motion requires careful consideration. Respiratory gating and autonomous respiration control methods are often used to reduce the tumor dose $(12,27)$. An internal target volume treatment plan based on the 4D CT images should be designed for additional effectiveness (28).

To conclude, at constant $\mathrm{A}$ and $\mathrm{T}$ values, lung tumor volume was demonstrated to be proportional to dose verification $\gamma$ analysis passing rate. Large tumors achieved high passing rates, and small tumors achieved low passing rates. At a constant tumor volume, a descending trend in passing rate with increasing A value was revealed. The respiratory period demonstrated no association with passing rate. Therefore, A values should be carefully controlled in clinical radiotherapy.

\section{Acknowledgements}

Not applicable.

\section{Funding}

The present study was supported by the Natural Science Foundation of Jiangsu Province Research of China (grant no. BK20151181), the High-Level Medical Talents Training Project of Changzhou (grant no. 2016CZLJ004) and the Municipal Social Development Project of the Changzhou City (grant no. CJ20160029).

\section{Availability of data and materials}

The datasets used and/or analysed during the current study are available from the corresponding author on reasonable request.

\section{Authors' contributions}

KX and XN designed the study. HS and TL collected the data. LG and JS performed the statistical analysis and helped to draft the manuscript. All authors approved the final version of the manuscript.

\section{Ethics approval and consent to participate}

The present study was approved by the Clinical Ethics Committee of Second People's Hospital of Changzhou of Nanjing Medical University (Changzhou, China). All patients provided written informed consent for their inclusion in the current study.

\section{Consent for publication}

All patients consented to publication.

\section{Competing interests}

The authors declare that there are no competing interests.

\section{Authors' information}

KX,HS, LG, TL, JS and XN are affiliated with the Radiotherapy Department, Second People's Hospital of Changzhou, Nanjing Medical University, Changzhou, Jiangsu 213003, P.R. China

\section{References}

1. Shi HS, Gao X, Li D, Zhang QW, Wang YS, Zheng Y, Cai LL, Zhong RM, Rui A, Li ZY, et al: A systemic administration of liposomal curcumin inhibits radiation pneumonitis and sensitizes lung carcinoma to radiation. Int J Nanomed 7: 2601-2611, 2012.

2. Li Y, Wang J, Tan L, Hui B, Ma X, Yan Y, Xue C, Shi X, Drokow EK and Ren J: Dosimetric comparison between IMRT and VMAT in irradiation for peripheral and central lung cancer. Oncol Lett 15: 3735-3745, 2018.

3. Sumida I, Yamaguchi H, Das IJ, Kizaki H, Aboshi K, Tsujii M, Yamada Y, Suzuki O, Seo Y, Isohashi F and Ogawa K: Intensity-modulated radiation therapy dose verification using fluence and portal imaging device. J Appl Clin Med Phys 17: 259-271, 2016.

4. Park JY, Lee JW, Choi KS, Lee JS, Kim YH, Hong S and Suh TS: Development of a novel quality assurance system based on rolled-up and rolled-out radiochromic films in volumetric modulated arc therapy. Med Phys 38: 6688-6696, 2011.

5. Tanooka M, Doi H, Miura H, Inoue H, Niwa Y, Takada Y, Fujiwara M, Sakai T, Sakamoto K and Kamikonya N: Three-dimensional radiochromic film dosimetry for volumetric modulated arc therapy using a spiral water phantom. J Radiat Res 54: 1153-1159, 2013.

6. Bucciolini M, Buonamici FB and Casati M: Verification of IMRT fields by film dosimetry. Med Phys 31: 161-168, 2004.

7. Gloi AM, Buchana RE, Zuge CL and Goettler AM: RapidArc quality assurance through MapCHECK. J Appl Clin Med Phys 12: 39-47, 2011.

8. Li QL, Deng XW, Chen LX, Huang XY and Huang SM: The angular dependence of a 2-dimensional diode array and the feasibility of its application in verifying the composite dose distribution of intensity-modulated radiation therapy. Chin J Cancer 29: 617-620, 2010.

9. Xin-Ye N, Ren L, Yan H and Yin FF: Sensitivity of 3D dose verification to multileaf collimator misalignments in stereotactic body radiation therapy of spinal tumor. Technol Cancer Res Treat 15: NP25-NP34, 2016.

10. He R and Yang C: SU-FF-T-359: MapPhan with MapCHECK and Im'RT MatriXX for real gantry angle IMRT QA. Medical Physics 36: 2604-2604, 2009. 
11. García-Vicente F, Fernández V, Bermúdez R, Gómez A, Pérez L, Zapatero A and Torres JJ: Sensitivity of a helical diode array device to delivery errors in IMRT treatment and establishment of tolerance level for pretreatment QA. J Appl Clin Med Phys 13: 3660,2012

12. Webb S: Motion effects in (intensity modulated) radiation therapy: A review. Phys Med Biol 51: R403-R425, 2006.

13. Starkschall G, Britton K, McAleer MF, Jeter MD, Kaus MR, Bzdusek K, Mohan R and Cox JD: Potential dosimetric benefits of four-dimensional radiation treatment planning. Int J Radiat Oncol Biol Phys 73: 1560-1565, 2009.

14. Keall PJ, Mageras GS, Balter JM, Emery RS, Forster KM, Jiang SB, Kapatoes JM, Low DA, Murphy MJ, Murray BR, et al: $\mathrm{T}$ The management of respiratory motion in radiation oncology report of AAPM task group 76. Med Phys 33: 3874-3900, 2006.

15. Duan J, Shen S, Fiveash JB, Popple RA and Brezovic IA Dosimetric and radiobiological impact of dose fractionation on respiratory motion induced IMRT delivery errors: A volumetric dose measurement study. Med Phys 33: 1380-1387, 2006

16. Low DA, Harms WB, Mutic S and Purdy JA: A technique for the quantitative evaluation of dose distributions. Med Phys 25: 656-661, 1998

17. Jiang SB, Pope C, Al Jarrah KM, Kung JH, Bortfeld T and Chen GT: An experimental investigation on intra-fractional organ motion effects in lung IMRT treatments. Phys Med Biol 48: 1773-1784, 2003.

18. Court L, Wagar M, Berbeco R, Reisner A, Winey B, Schofield D, Ionascu D, Allen AM, Popple R and Lingos T: Evaluation of the interplay effect when using RapidArc to treat targets moving in the craniocaudal or right-left direction. Med Phys 37: 4-11, 2010.

19. Newhauser W: ICRU PRESCRIBING, recording and reporting photon beam therapy. international commissions on radiation units and measurements (Supplement to ICRU report 50): Bethesda, MD, USA. Report 62. Radiation Protection Dosimetry 133: 60-62, 2009.
20. Langen KM and Jones DT: Organ motion and its management. Int J Radiat Oncol Biol Phys 50: 265-278, 2001.

21. Ozhasoglu C and Murphy MJ: Issues in respiratory motion compensation during external-beam radiotherapy. Int J Radiat Oncol Biol Phys 52: 1389-1399, 2002.

22. Shimizu S, Shirato H, Ogura S, Akita-Dosaka H, Kitamura K, Nishioka T, Kagei K, Nishimura M and Miyasaka K: Detection of lung tumor movement in real-time tumor-tracking radiotherapy. Int J Radiat Oncol Biol Phys 51: 304-310, 2001.

23. Seco J, Sharp GC, Turcotte J, Gierga D, Bortfeld T and Paganetti H: Effects of organ motion on IMRT treatments with segments of few monitor units. Med Phys 34: 923-934, 2007.

24. Happersett L, Mageras GS, Zelefsky MJ, Burman CM, Leibel SA, Chui C, Fuks Z, Bull S, Ling CC and Kutcher GJ: A study of the effects of internal organ motion on dose escalation in conformal prostate treatments. Radiother Oncol 66: 263-270, 2003.

25. Bortfeld T, Jiang SB and Rietzel E: Effects of motion on the total dose distribution. Semin Radiat Oncol 14: 41-51, 2004.

26. Schaefer M, Münter MW, Thilmann C, Sterzing F, Haering P, Combs SE and Debus J: Influence of intra-fractional breathing movement in step-and-shoot IMRT. Phys Med Biol 49: N175-N179, 2004.

27. Korreman SS: Motion in radiotherapy: Photon therapy. Phys Med Biol 57: R161-R191, 2012.

28. Yoon MS, Jeong JU, Nam TK, Ahn SJ, Chung WK and Song JY: Evaluation of dose distribution in intensity modulated radiosurgery for lung cancer under condition of respiratory motion. PLoS One 11: e0163112, 2016

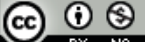

This work is licensed under a Creative Commons Attribution 4.0 International (CC BY-NC 4.0) License 